www.volsu.ru

DOI: https://doi.org/10.15688/nsr.jvolsu.2018.4.2

UDC 612.062

LBC 28.707.3

\title{
FUNCTIONAL CHARACTERISTICS OF THE RESPIRATORY SYSTEM OF PEOPLE OF ALL AGES ${ }^{1}$
}

\author{
Igor B. Isupov \\ Volgograd State University, Volgograd, Russian Federation \\ Julia A. Syagailo \\ Volgograd State University, Volgograd, Russian Federation \\ Artem A. Mazembah \\ Volgograd State University, Volgograd, Russian Federation
}

\begin{abstract}
Studies of the functional state of the respiratory system have been widely used to assess the adaptive reserves of the human body. The functional state of the respiratory system is closely related to the functional characteristics of systemic and regional hemodynamics, functional reserves of the blood system. With changes in the social status of a person, the adaptive potential of his body can significantly decrease. Reliable markers of the limitations of adaptive potential in people of different ages are the decrease in the values of the main pulmonary volumes in the conditions of physiological rest and when performing test load tests. The negative dynamics of forced expirations due to the decrease in the strength of the auxiliary respiratory muscles and changing depending on age was established. The presence of this undesirable phenomenon can be a marker of reducing adaptation reserves in the study of the impact of environmental factors on the phenomenon of premature aging.

Key words: respiratory system, spirometry, forced expirations, pulmonary volumes, vital capacity of lungs, premature aging.
\end{abstract}

УДК 612.062

ББК 28.707 .3

\section{ФУНКЦИОНАЛЬНЫЕ ХАРАКТЕРИСТИКИ РЕСПИРАТОРНОЙ СИСТЕМЫ ЛЮДЕЙ РАЗЛИЧНОГО ВОЗРАСТА ${ }^{1}$}

\author{
Игорь Борисович Исупов \\ Волгоградский государственный университет, г. Волгоград, Российская Федерация \\ Юлия Алексеевна Сягайло \\ Волгоградский государственный университет, г. Волгоград, Российская Федерация \\ Артем Александрович Мазембах \\ Волгоградский государственный университет, г. Волгоград, Российская Федерация
}

Аннотация. Исследования функционального состояния респираторной системы нашли широкое при-
сение для оценки адаптационных резервов организма человека. Функциональное состояние респиратор-
системы находится в тесной связи с функциональными характеристиками системной и регионарной
адаптационный потенциал его организма может значительно снижаться. Надежными маркерами ограни-
сй адаптационного потенциала у людей различного возраста являются снижение величин основных ле- 
новлена негативная динамика показателей форсированной экспирации, обусловленная снижением силы вспомогательных дыхательных мышц и изменяющаяся в зависимости от возраста. Наличие данного нежелательного феномена может являться маркером снижения адаптационных резервов при изучении влияния экологических факторов на феномен преждевременного старения.

Ключевые слова: респираторная система, спирометрия, преждевременное старение.

Волгоградский регион, составляя часть Юга Европейской территории России (ЕТР), характеризуется гипокомфортными, частично прекомфортными природными условиями. Отмечаемый неуклонный рост антропогенного воздействия на природные ландшафты Юга ЕТР обусловливает увеличение социальной и экологической напряженности, что непосредственно сказывается и на состоянии популяционного здоровья местного населения. Особую актуальность в указанных условиях приобретает проблема обеспечения региональной безопасности трудоспособного населения [4].

Известно определенное число научных работ, посвященных проблематике социальной и профессиональной адаптации студентов к процессам обучения в высшей школе [3, 5 , 6-9]. Примером частных удачных изысканий в указанном направлении является развернутый, высокопродуктивный анализ основных характеристик здоровья студентов не технического профессионального направления, в том числе иностранных граждан при адаптации их к условиям жизни и обучения в университетах Волгоградского региона $[5,6]$. Авторы уделяют особое внимание особенностям адаптации системы кровообращения, динамике биохимических показателей и морфометрических параметров молодых людей, в том числе иностранных граждан, проживающих в нашей стране и находящихся в состоянии своеобразного «латентного стресса».

Респираторная система человека является важнейшим звеном в цепи сопряженных функций систем крови, кровообращения и метаболизма в целом. Снижение вентиляции альвеолярных пространств легких, вызванное различными стресс-факторам, является негативным процессом, ограничивающим альвеолярно-капиллярный газообмен и, как следствие, снижающим тканевой метаболизм $[1,6]$. Компенсаторные механизмы системной адаптации, отчасти парирующие ограничение легочной вентиляции, изначально направлены на повышение хронотропной, инотропной, насосной функций сердца и, далее, на возрастание объема циркулирующей крови и ее кислородной емкости. Таким образом, спирометрические исследования функционального состояния внешнего дыхания имеют потенциально высокую ценность для наиболее раннего обнаружения феномена системной дизадаптации организма людей различного возраста, а также темпов естественного старения $[1,4,6]$.

В то же время одномоментная спирометрия не всегда обеспечивает надежный контроль состоятельности вентиляции легких человека, испытывающего воздействие стрессфакторов социального происхождения. В связи с изложенным, несомненную актуальность приобретает выполнение функциональных обследований легких, реализуемых по схеме «обычная спирометрия» - «форсированная спирометрия» в динамике тестовых нагрузочных проб. Не менее очевидно, что обследования функциональных резервов системы дыхания наиболее востребованы в важнейшие периоды жизни молодого человека: на этапе адаптации к факторам образовательной среды высшего учебного заведения, на этапе профессионального самоопределения и становления $[1,6]$.

В связи с изложенным, цель работы определена следующим образом: системный анализ функционального состояния респираторной системы у людей различного возраста в условиях относительного покоя, а также при выполнении тестовых нагрузочных проб.

Материалы и методы. Под наблюдением находились 14 студентов института естественных наук Волгоградского государственного университета (1-я группа; возраст $18,6 \pm 0,8$ лет) и 18 представителей трудоспособного населения (2-я группа; возраст $32,2 \pm 0,4$ лет). Выполнение экспериментальной части исследований обеспечивалось соблюдением принципа информированного согласия обследуемых, что достигалось информированием об условиях проведения исследования и ис- 
И.Б. Исупов, Ю.А. Сягайло, А.А. Мазембах. Функциональные характеристики респираторной системы людей

пользуемых методиках, сообщением о гарантиях неразглашения полученной информации.

Методом обычной и форсированной спирометрии у обследуемых обеих возрастных групп определяли: жизненную емкость легких в фазу экспирации (ЖЕЛ, л), экспираторную форсированную жизненную емкость легких (ЭФЖЕЛ, л), экспираторную форсированную жизненную емкость легких за первую секунду форсированного выдоха (ЭФЖЕЛ, , л/с), резервный объем выдоха (РОвыд, л), форсированный резервный объем выдоха (ФРОвыд, л).

Измерения легочных объемов выполнены с помощью прибора «дифференциальный электронный спирометр - ДЭС» и АПК «Валента» модуль «Функции внешнего дыхания» [2]. Все исследования проведены в первой декаде ноябре 2018 г.

Наблюдения выполнены в три этапа:

1. Обычная и форсированная спирометрия в положении стоя, после десятиминутного отдыха.

2. Обычная и форсированная спирометрия на 1-й минуте после самостоятельного перемещения обследуемых в положение лежа на спине.

3. Обычная и форсированная спирометрия в положении стоя, на 1-й минуте периода восстановления после завершения пробы Мартине (20 приседаний за 20 c).

Статистический анализ первичных данных выполнен с помощью программного пакета «SPSS 18», с помощью которого определяли среднюю арифметическую величину каждого параметра (M), ошибку средней арифметической (m). Достоверность различий динамики параметров спирометрии на различных этапах обследований определяли согласно величинам t-критерия Стьюдента.

Результаты и их обсуждение. У студентов параметры обычной и форсированной спирометрии, измеренные в положении стоя, были несколько ниже возрастных нормативов, что обусловлено низкой физической тренированностью молодых людей.

Переход обследуемых в положение лежа на спине сопровождался несущественной и разнонаправленной динамикой индивидуальных величин ЖЕЛ, ЭФЖЕЛ, ЭФЖЕЛ, , РОВЫД и ФРОвыд. Однако средние значения всех показателей недостоверно отличались от исходного уровня (см. таблицу).

Несколько более выражена и своеобразна динамика параметров форсированной экспирации обследуемых 1-й группы после теста Мартине. Обнаружено, что ЭФЖЕЛ, РОвыд и ФРОвыд на 1-й минуте восстановления после физической нагрузки достоверно возрастали (соответственно, на 19,3\% $(\mathrm{p}<0,046)$, $21,9 \%(\mathrm{p}<0,04)$ и $38,7 \%(\mathrm{p}<0,021))$ по сравнению с исходным уровнем.

Таким образом, у обследуемых студентов проба с физической нагрузкой оказывает наиболее существенное влияние на скоростные характеристики экспирации, способствуя их увеличению. Вероятно, этот феномен обусловлен своеобразным «тренирующим эффектом» физических нагрузок малой интенсивности, способствующим некоторому повышению тонуса и сократительной способности вспомогательных дыхательных мышц, мускулатуры брюшного пресса.

Легочные объемы студентов-первокурсников на различных этапах наблюдений $(\mathbf{M} \pm \mathbf{m}, \mathbf{n}=\mathbf{1 4})$

\begin{tabular}{|l|c|c|c|c|c|}
\hline \multirow{2}{*}{ Этап наблюдений } & \multicolumn{5}{|c|}{ Параметр спирометрии } \\
\cline { 2 - 6 } & ЖЕЛ, л & ЭФЖЕЛ, л/с & ЭФЖЕЛ, л/с & РОвыд, л & ФРОвыд, л \\
\hline Покой, стоя & 2,54 & 2,35 & 1,61 & 0,96 & 1,11 \\
& \pm & \pm & \pm & \pm & \pm \\
& 0,21 & 0,18 & 0,09 & 0,06 & 0,13 \\
\hline Покой, лежа на спине & 2,44 & 2,07 & 1,70 & 0,95 & 1,08 \\
& \pm & \pm & \pm & \pm & \pm \\
& 0,16 & $0,15 \#$ & 0,12 & 0,09 & 0,10 \\
\hline 1-я минуга восста- & $2,88 \pm$ & $2,40 \pm$ & $1,92 \pm$ & $1,17 \pm$ & $1,54 \pm$ \\
новления после теста & $0,16 \#$ & 0,13 & $0,12 *$ & $0,08 *$ & $0,13 *$ \\
Мартине & & & & & \\
\hline
\end{tabular}

Примечания. Знаком «*» отмечена достоверность различий параметра по сравнению с его значением в положении стоя (покой); $<<0,05$ и более. Знак «\#»-тенденция изменений параметра $(\mathrm{p}=0,06-0,07)$. 
Анализ первичных данных спирометрии обследуемых 2-й группы показал, что в условиях относительного покоя (стоя) величины ЖЕЛ, ЭФЖЕЛ, ЭФЖЕЛ, , а также резервный объем выдоха соответствовали возрастным нормативам. В то же время было обнаружено значительное снижение форсированного резервного объема выдоха по сравнению с $\mathrm{PO}_{\text {выд }}$, полученным обычным (не форсированным) методическим приемом, что свидетельствует о нарушениях вентиляции легких. Переход в положение лежа на спине сопровождался снижением ЖЕЛ (на $15,8 \%$; $>0,05$ ). Величины ЭФЖЕЛ и ЭФЖЕЛ 1 изменялись незначительно, однако $\mathrm{PO}_{\text {выд }}$ снижался на $33,8 \%$, ФРО выд оставался практически на прежнем уровне.

Наиболее выражена динамика показателей спирометрии была выявлена у обследуемых 2-ой группы после завершения теста Мартине. ЖЕЛ снизилась на $32,4 \%(p=0,045)$, ЭФЖЕЛ - на 42,3 \% $(\mathrm{p}<0,01)$; ЭФЖЕЛ была меньше исходного уровня на $35,7 \%(\mathrm{p}<0,032)$. Существенно, на 45,2 \% ( $<<0,018)$ уменьшился $\mathrm{PO}_{\text {выд }}$ Выявлено достоверное снижение ФРО

Таким образом, по завершении теста с 20 приседаниями, у обследуемых - представителей трудоспособного населения наиболее существенно снижались параметры форсированной спирометрии, характеризующие проходимость трахеобронхиального дерева и скоростно-силовые качества вспомогательных дыхательных мышц (наружных межреберных и мускулатуры брюшной стенки). По-видимому, это являлось следствием низкого уровня физического состояния большинства обследованных, у которых проведение теста Мартине вызывает выраженную одышку и, как результат этого, неспособность выполнения максимально глубокого вдоха, необходимого для последующей форсированной экспирации.

Указанный феномен может служить своеобразным маркером напряжения респираторных механизмов, обеспечивающих дыхательный каскад реакций в обеспечении организма кислородом и являться критерием преждевременного старения.

Заключение. Качество жизни обучающейся молодежи и людей трудоспособного возраста в значительной мере определяется успешностью адаптации к длительным умственным, эмоциональным и смешанным нагрузкам, сопровождающим смену социального статуса человека.

Функциональное состояние респираторной системы, оперативно реагирующей на действие констелляций стресс-факторов, позволяет судить о развитии негативных процессов, возникновении признаков дизрегуляции многих морфофункциональных систем организма. В контексте изложенного, для разработки новых приемов оценки функционального состояния трахеобронхиального дерева исключительно актуальна правильная, этапная, «пошаговая» тактика выполнения спирометрических исследований важнейших легочных объемов.

Проведенные многоэтапные спирометрические исследования обычной и форсированной экспирации у молодых людей позволили выявить снижение резервов силы и сократимости вспомогательной экспираторной дыхательной мускулатуры (косых, поперечных, прямых мышц брюшной стенки; мышц, сгибающих позвоночник).

Выявленное в динамике наблюдения снижение форсированной экспираторной жизненной емкости легких, ее секундной фракции, обычного и форсированного резервных объемов выдоха после выполнения несложного теста с физической нагрузкой у молодых лиц трудоспособного населения, на наш взгляд, может являться индикатором ограничений адаптационных резервов их организма в целом и, отчасти, судить о физическом состоянии организма в целом.

Студенты, судя по результатам настоящей работы, характеризуются более благоприятными реакциями респираторной системы на примененные тестовые воздействия, о чем свидетельствует положительная динамика форсированных экспираторных объемов после завершения теста Мартине. Дальнейшие комплексные наблюдения, проводимые повторно в различное время года, возможно, позволят уточнить количественно-качественные характеристики изменений легочных объемов у людей различных возрастов в динамике длительной адаптации к изменениям социального статуса и создать предпосылки к разработкам новых прогностических моделей их соматического здоровья. 
И.Б. Исупов, Ю.А. Сягайло, А.А. Мазембах. Функциональные характеристики респираторной системы людей

\section{ПРИМЕЧАНИЕ}

\author{
1 Работа выполнена при поддержке гранта \\ РФФИ(№ 18-413-340005).
}

\section{СПИСОК ЛИТЕРАТУРЫ}

1. Исупов, И.Б. Возрастные особенности показателей форсированного дыхания / И.Б. Исупов, Е.Ю. Надежкина, О.С. Филимонова // Клиническая геронтология. - 2013. - Т. 19, № 7-8. C. 31-33.

2. Исупов, И.Б. Создание и совершенствование учебных приборов междисциплинарного назначения как составная часть модернизации образовательного процесса (Опыт конструирования. Обобщение): монография / И.Б. Исупов. - Волгоград: изд-во ВГАПО, 2015. - 224 с.

3. Севрюкова, Г.А. Функциональное состояние и регуляторно-адаптивные возможности организма человека /Г.А. Севрюкова, Г.М. Коновалова. - Волгоград: изд-во ВолгГТУ, 2015. - 104 с.

4. Севрюкова, Г.А. Экология. Адаптация. Человек/Г.А. Севрюкова, Ю.Н. Картушина, В.Ф. Желтобрюхов. - Волгоград: изд-во ВолгГТУ, 2018. $76 \mathrm{c}$.

5. Севрюкова, Г.А. Функциональное состояние мозгового кровообращения в зависимости от локализации переходной зоны в грудных отведениях ЭКГ на фоне активной ортостатической пробы /Г.А. Севрюкова, Г.Э. Настинова, Л.А. Товмасян, П.Л. Севрюкова //Наука. Инновации. Технологии. 2018. - № 1. - С. 211-220.

6. Экспираторные легочные объемы молодых людей в условиях покоя и в период восстановления после дозированной физической нагрузки / И.Б. Исупов, Г.А. Севрюкова, Я.Г. Шмарина, К.А. Ряскова, В.А. Белова // Известия Саратовского университета. Новая серия. Серия: Химия. Биология. Экология. 2017. - T. 17, № 2. - C. 197-200.

7. Academic exam stress and depressive mood are associated with reductions in exhaled nitric oxide in healthy individuals /A.F. Truebaa, N.B. Smitha, R.J. Auchusb, T. Ritz //Bio Psychology. - 2013: 93 (1): 206-212.

8. Sharma B. Academic stress due to depression among medical and para-medical students in an indian medical college: health initiatives cross sectional study /B. Sharma, R. Wavare//J. of Health Sciences. - 2013. T. 3, № 5 (15). - C. 029-038.

9. Fazaila S. Assessment of stress among physiotherapy students at Riphah Centre of Rehabilitation Sciences /S. Fazaila, R.S. Farah, N.B. Muhammad //J. Pak Med Asso. - 2013; 63 (3): 346-349.

\section{REFERENCES}

1. Isupov I.B., Nadezhkina E.YU., Filimonova O.S. Vozrastnye osobennosti pokazatelej forsirovannogo dyhaniya [Age-specific indicators of forced respiration] //Klinicheskaya gerontologiya, 2013, vol. 19, no 7-8, pp. 31-33.

2. Isupov I.B. Sozdanie i sovershenstvovanie uchebnyh priborov mezhdisciplinarnogo naznacheniya kak sostavnaya chast' modernizacii obrazovatel'nogo processa (Opyt konstruirovaniya. Obobshhenie) [Creation and improvement of educational devices for interdisciplinary purposes as an integral part of the modernization of the educational process (Design experience. Generalization)] Volgograd: izd-vo VGAPO, 2015, 224 p.

3. Sevriukova G.A., Konovalova G.M. Funkcional'noe sostoyanie i regulyatorno-adaptivnye vozmozhnosti organizma cheloveka [Functional state and regulatory and adaptive capabilities of the human body] Volgograd: izd-vo VolgGTU, 2015, 104 p.

4. Sevriukova G.A., Kartushina YU.N., ZHeltobryuhov V.F. Ekologiya. Adaptaciya. Chelovek [Ecology. Adaptation. Man] Volgograd: izd-vo VolgGTU, 2018. 76p.

5. Sevriukova G.A., Nastinova G.E., Tovmasyan L.A., Sevriukova P.L. Funkcional'noe sostoyanie mozgovogo krovoobrashheniya $\mathrm{v}$ zavisimosti ot lokalizacii perekhodnoj zony $\mathrm{v}$ grudnyh otvedeniyah EKG na fone aktivnoj ortostaticheskoj proby [The Functional State of the Cerebral Circulation Depending on the Localization of Transition Area in Chest Lead of ECG at Orthostasis] //Nauka. Innovacii. Tekhnologii, 2018. no 1, pp. 211-220.

6. Isupov I.B., Sevryukova G.A., SHmarina YA.G., Ryaskova K.A., Belova V.A. Ekspiratornye legochnye oblemy molodyh lyudej v usloviyah pokoya i v period vosstanovleniya posle dozirovannoj fizicheskoj nagruzki [Expiratory Lung Volumes of Young People at Rest and Recovery Period after a Dosed Physical Load]//Izvestiya Saratovskogo universiteta. Novaya seriya. Seriya: Himiya. Biologiya. Ekologiya, 2017, vol. 17, no 2. pp. 197-200.

7. Truebaa A.F., Smitha N.B., Auchusb R.J., Ritz T. Academic exam stress and depressive mood are associated with reductions in exhaled nitric oxide in healthy individuals //Bio Psychology, 2013, vol. 93 (1), pp. 206-212.

8. Sharma B., Wavare R. Academic stress due to depression among medical and para-medical students in an indian medical college: health initiatives cross sectional study //J. of Health Sciences, 2013, vol. 3, no 5 (15), pp. 029-038.

9. Fazaila S., Farah R.S., Muhammad N.B. Assessment of stress among physiotherapy students at Riphah Centre of Rehabilitation Sciences //J. Pak Med Asso, 2013, vol. 63 (3), pp. 346-349. 


\section{БИОЛОГИЯ И БИОТЕХНОЛОГИЯ}

\section{Information about the Authors}

Igor B. Isupov, Doctor of Sciences (Medicine), Professor Department of biology, Volgograd State University, Prosp. Universitetsky, 100, 400062 Volgograd, Russian Federation, igor.isupov.66@outlook.com.

Julia A. Syagailo, Student, Department of Biology, Volgograd State University, Prosp. Universitetskij, 100, 400062 Volgograd, Russian Federation, syagailo2010@yandex.ru.

Artem A. Mazembah, Student, Department of Biology, Volgograd State University, Prospekt Universitetskij, 100, 400062 Volgograd, Russian Federation, artem_masemb@mail.ru.

\section{Информация об авторах}

Игорь Борисович Исупов, доктор медицинских наук, профессор кафедры биологии, Волгоградский государственныый университет, просп. Университетский, 100, 400062 г. Волгоград, Российская Федерация, igor.isupov.66@outlook.com.

Юлия Алексеевна Сягайло, студентка кафедры биологии, Волгоградский государственный университет, просп. Университетский, 100, 400062 г. Волгоград, Российская Федерация, syagailo2010@yandex.ru.

Артем Александрович Мазембах, студент кафедры биологии, Волгоградский государственный университет, просп. Университетский, 100, 400062 г. Волгоград, Российская Федерация, artem_masemb@mail.ru. 